\title{
Los Incas en el Collasuyu. Notas sobre alianzas prehispánicas en el área andina argentina
}

\author{
The Incas in the Collasuyu. \\ Notes on pre-Hispanic alliances in the Argentine Andean area \\ Margarita E. GENTILE LAFAILLE \\ Ex Profesor titular ordinario, Cátedra Instituciones \\ del Periodo Colonial e Independiente. \\ Universidad Nacional de las Artes, Buenos Aires. \\ margagentile@yahoo.com.ar
}

Resumen: El propósito de este ensayo es retomar el tema de los Incas en el Collasuyu, sector sudeste del Tahuantinsuyu, mediante aproximaciones al estudio de la capacocha, ceremonia fundacional de una alianza validada por un oráculo que podía ser consultado desde el Cusco. Veremos a través de cuatro casos dos de sus tipos: acuerdo entre el Inca y sus aliados, y acuerdo entre jefes regionales aliados entre sí.

La Arqueología mostró la forma de estos acuerdos, y la Etnohistoria aportó microsecuencias de la realización de la ceremonia, rangos de sus participantes, los marcadores de la filiación incaica, etcétera.

Abstract: The purpose of this essay is to return to the subject of the Incas in Collasuyu, in the southeast sector of Tahuantinsuyu, through approaches to the study of the capacocha, the founding ceremony of an alliance validated by an oracle that could be consulted from Cusco. We will see through four cases two of their types: agreement between the Inca and his allies, and agreement between regional leaders allied with each other.

Archeology showed the form of these agreements, and Ethnohistory provided microsequences of the performance of the ceremony, ranks of its participants, the markers of Inca filiation, etc. 
Palabras clave: capacocha; Doncellas; Rachaite; Aconcagua; Llullaillaco; Tahuantinsuyu; Collasuyu; Incas; alianzas; atuendos; colores.

Keywords: capacocha; Doncellas; Rachaite; Aconcagua; Llullaillaco; Tahuantinsuyu; Collasuyu; Incas; alliances; garments; colours.

\section{Sumario:}

I. El tema y su interés.

II. Sitio Doncellas / Rachaite, puna de Jujuy.

III. Cerro Aconcagua, Andes de Mendoza.

IV. Volcán Llullaillaco, puna de Salta.

4.1. Vestuario femenino.

4.2. Vestuario masculino.

4.3. Música, recitado, canto.

4.4. Orden en el vestir de los atuendos.

4.5. Léxico de los elementos de vestuario.

4.6. Creencias andinas y europeas acerca de los volcanes.

4.7. Gráfica incaica / ¿lengua secreta de los Incas?

V. Cronología relativa.

VI. Bibliografía.

Recibido: agosto 2020.

Aceptado: octubre 2020. 


\section{EL TEMA Y SU INTERÉS}

El propósito de este ensayo es ampliar el tema de la presencia incaica en el Collasuyu, sector sudeste del Tahuantinsuyu, a través de nuevas aproximaciones al estudio de la capacocha, ceremonia fundacional de una alianza validada por un oráculo que podía ser consultado desde el Cusco ${ }^{1}$. Se tendrán en cuenta dos tipos: el acuerdo entre el Inca y sus aliados, y el acuerdo entre jefes regionales (curacuna) aliados entre sí.

Los avances logrados en la primera etapa del Proyecto "Estudio..." trazaron con más nitidez algunas continuidades y cambios que ya había observado en la capacocha del cerro Aconcagua, y me permitieron reconocer dos variantes locales de la misma ceremonia en Doncellas / Rachaite.

Los cuatro casos considerados aqui siguen un orden cronológico relativo -faltan fechados absolutos puntuales- según lo que hasta ahora se sabe acerca de los desarrollos regionales preincaicos y la expansión del Tahuantinsuyu ${ }^{2}$. Reajusté algunas expresiones de mis trabajos previos porque hoy se sabe más sobre la capacocha incaica. Las excavaciones, asimismo, se encararon de diferentes maneras; sin tratar en detalle ese aspecto debo notar que lo tuve en cuenta.

Tanto en Doncellas / Rachaite como en Aconcagua y Llullaillaco, la Arqueología mostró la forma de este tipo de acuerdos. Pero Aconcagua y Llullaillaco aportaron a la Etnohistoria de la capacocha microsecuencias de la realización de la ceremonia, rangos de sus participantes y uno de los marcadores

${ }^{1}$ GENTILE LAFAILLE, M.E., "La fundación incaica del oráculo capacocha en el Collasuyu: secuelas de una nota a pie de página”, en Revista Cruz del Sur (San Isidro, prov. de Buenos Aires), 22 (2017a) 11-83.

${ }^{2}$ Entre otros, GONZÁLEZ, A.R., "Patrones de asentamiento incaico en una provincia marginal del imperio", en Revista Relaciones de la Sociedad Argentina de Antropología (Buenos Aires), XIV (1) (1980) 63-82. GONZÁLEZ, A.R., "Las 'provincias' Inca del antiguo Tucumán”, en Revista del Museo Nacional (Lima), XLVI (1982) 317-380. RAFFINO, R.A., Los Inkas del Kollasuyu. Origen, naturaleza y transfiguraciones de la ocupación inka en los Andes meridionales, La Plata (provincia de Buenos Aires) 1982. 
de la filiación incaica: las estatuillas de camélidos de metal y valva de molusco color rojo (Spondylus, mullu); y cierto tipo de estatuillas antropomorfas, en los mismos materiales, vestidas de determinada manera con cierto tipo de ropa.

Estas miniaturas ajustaron la cronología interna del Tahuantinsuyu porque estilo y tecnología de manufacturas corresponden a las de los artesanos especializados chimú y collas, regiones conquistadas por Topa Inca Yupanqui. Asimismo, marcaron la diferencia con las estatuillas que los buscadores de objetos prehispánicos (huaqueros) revisten con cualquier prenda para mejorar sus ventas, y las que algunos fabricaban en metal.

En otro orden, la conservación de los textiles miniatura de Aconcagua y Llullaillaco es más que buena -los hallados en los cráteres de volcanes activos perdieron forma, color y textura-, lo que facilita su estudio.

Indagar acerca de la capacocha es aproximarse, en lo posible, a la razón de ser de dicha ceremonia. Folklore, Etnografía y Lingüística, como partes de los estudios de Etnohistoria, no podían desestimarse. El contexto muestra que las personas halladas en Aconcagua y Llullaillaco fueron transfiguradas en divinidades andinas (huacas) tras haber participado de una compleja ceremonia. No son ofrendas ni sacrificios, y no vale aquí usar la palabra "entierro".

La continuidad de estas creencias en los registros de Folklore y Etnografia da que en el interior de los cerros andinos destacados habitan jefes descendientes de los Incas (auquicuna) y el cerro mismo, que los gobierna (apu); todos ellos están vivos, pueden revestir formas humanas o animales y, en ciertas circunstancias, hacerse visibles y dialogar con los humanos. Esta creencia se difundió desde la fundación del Tahuantinsuyu, por lo menos. Entroncó con la vulgarización de relatos clásicos traídos por los europeos ${ }^{3}$ y derivó en la sencilla afirmación de que se trató de sacrificios humanos, una de las justificaciones a la conquista, colonización y evangelización del Tahuantinsuyu.

En lo que sigue expondré cuatro evidencias de acuerdos entre grupos andinos prehispánicos con un oráculo como reaseguro de la mutua fidelidad a lo acordado. En ninguno de los casos se halló una pichca, que era el objeto mediante el cual se consultaba el oráculo ${ }^{4}$, probablemente porque el mismo lo llevaba consigo el consultante.

${ }^{3}$ Ifigenia, de Eurípides, por ejemplo; aunque Ovidio resolvió el cuento de otra manera, diciendo que Diana se dio por contenta con su reemplazo por una cierva en el altar. Las Metamorfosis era una colección de cuentos basados en creencias precristianas muy popular desde antes del quinientos, y después también.

${ }^{4}$ GENTILE, M.E., "La pichca: oráculo y juego de fortuna (su persistencia en el espacio y tiempo andinos)", en Boletín del Instituto Francés de Estudios Andinos (Lima), 27 (1) (1998) 75-131. 


\section{SITIO DONCELLAS / RACHAITE, PUNA DE JUJUY (3900 m.s.n.m)}

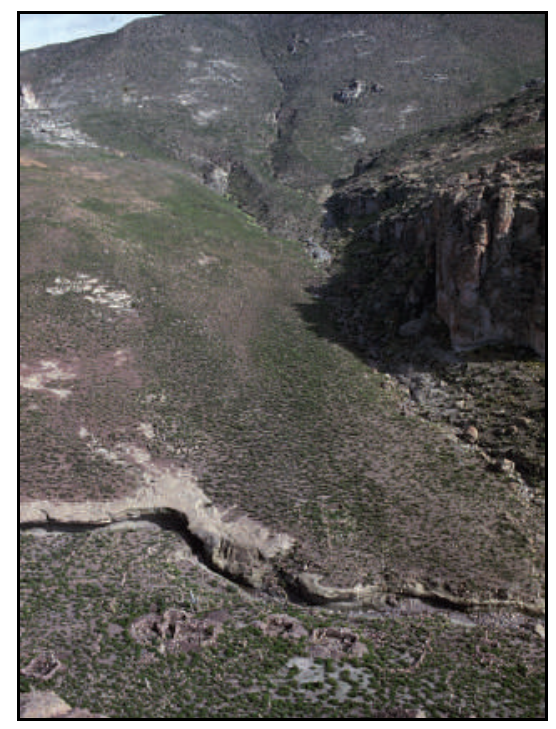

Figura 1. Vista parcial del Yacimiento del Río Doncellas desde la cima del farallón sur de la Roca Central / Peña Fiera, hacia el norte. En la planicie, cortada por la cárcava, se ven algunos de los recintos ya excavados. Foto M.E. Gentile.

A partir de Aconcagua, confirmado en Llullaillaco, fue posible reconocer los elementos mínimos de una capacocha en sitios que no fuesen la cima de un nevado: niños en un espacio intencionalmente limitado, formando grupo y acompañados con camélidos. Estos aspectos formales se notan en dos conjuntos de Doncellas / Rachaite en los que la impronta incaica no tiene registro por Arqueología, aportando con eso a los estudios comparativos de la Historia prehispánica y colonial de un sitio poco indagado mediante excavaciones controladas.

Un caso lo señalé en 2003. Veámoslo más de cerca. En el sector 3 del sitio Doncellas / Rachaite, en el recinto 3, el más pequeño de todos con 2,50 x $1,20 \mathrm{~m}$, a partir de $0,90 \mathrm{~cm}$ hasta $1,30 \mathrm{~m}$ de profundidad se hallaron dos vasijas estilo Puna Tricolor que contenían, cada una, restos de un niño y una olla utilitaria que contenía otro. En total, en ese recinto se hallaron siete vasijas estilo Puna Tricolor y una olla ennegrecida, además de una pala de piedra y la embocadura de una trompeta de hueso ${ }^{5}$.

\footnotetext{
${ }^{5}$ En ALFARO de LANZONE, L.C., y SUETTA, J.M., "Excavaciones en la cuenca del río Doncellas", en Revista Antiquitas (Buenos Aires), XXII-XXIII (1976) p.18 dice: "tres vasos con decoración polícroma". El estilo Puna Tricolor en ALFARO de LANZONE, L.C., Investigación
} 


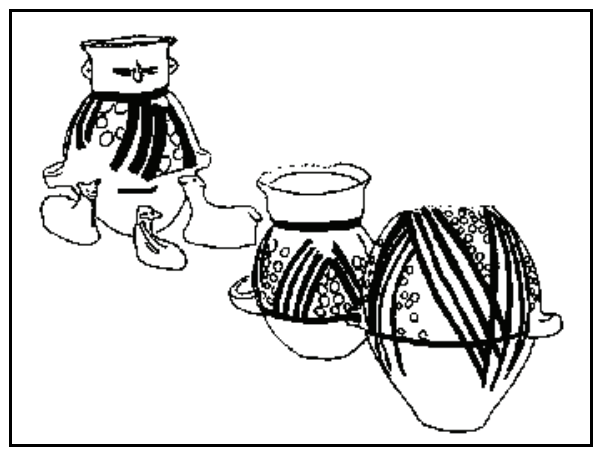

Figura 2. Reconstrucción parcial e ideal de una capacocha en el Yacimiento del Río Doncellas (Gentile, 2003, p.233, fig.13), basada en la descripción de Alfaro y Suetta (1976, pp.17-18; Alfaro, 1988, p.40).

La vasija Puna Tricolor que tiene un rostro en relieve estaba vacía; junto a ella había tres vasijas huecas y vacías en forma de camélidos (hulti). Éstas, que se conocían por fragmentos, se encontraron por primera vez completas y asociadas ${ }^{6}$. Propuse que el conjunto correspondía a una capacocha por contar con los elementos mínimos que hacen a dicha ceremonia ${ }^{7}$. Tras ser una alfarería poco común, la cantidad de vasijas Puna Tricolor en el R3 es extraordinaria; también llama la atención porque representan un personaje que viste ropa recamada con placas redondas de color blanco o negro pero que en fragmentos de alfarería hallados en otros sitios cercanos también son de colores negro y amarillo $^{8}$. Las primeras podrían ser como las que se encontraron al pie de un farallón en Doncellas / Rachaite: redondas, de plata ${ }^{9}$. Las de color negro, como las lentejuelas de mica que acompañaban un entierro de niño en Pucará de Rinconada $^{10}$, sitio donde también se halló un fragmento de Puna Tricolor con redondeles ocre. En cuanto a las placas de oro, tal vez fueran como una chapa redondeada y con cuatro huecos, como para ser cosida a una tela, hallada por

en la cuenca del río Doncellas, Depto.Cochinoca, Pcia.de Jujuy. Reconstrucción de una cultura olvidada en la Puna Jujeña, Jujuy 1988, pp. 39-40; 93-94.

${ }^{6}$ GENTILE, M.E., "Hulti - Acerca del uso de cierta alfarería Tiwanaku expansivo", en Revista Relaciones de la Sociedad Argentina de Antropología (Buenos Aires), XVI (1985) 205-220.

${ }^{7}$ GENTILE, M.E., 2003, p. 233.

${ }^{8}$ ALFARO y SUETTA, 1976, p.18. ALFARO, 1988, pp.93-94.

9 ROLANDI DE PERROT, D., "Un hallazgo de objetos metálicos en el área del Río Doncellas, Jujuy", en Revista Relaciones de la Sociedad Argentina de Antropología (Buenos Aires), VIII (1974) 153-160.

${ }^{10}$ SUETTA, J.M., y ALFARO DE LANZONE, L.C., "Excavaciones arqueológicas en el Pucará de Rinconada, provincia de Jujuy", en Actas de las Jornadas de Arqueología del Noroeste Argentino, Buenos Aires 1979, p. 333. ALFARO DE LANZONE, L.C., y SUETTA, J.M., "Nuevos aportes para el estudio del asentamiento humano en la puna de Jujuy. Revisión del Pucará de Rinconada”, en Revista Antiquitas (Buenos Aires), X (1970) 1-10. 
P.G. Haedo dentro de la tumba colectiva (chulpa) del Yacimiento LVII, que figura en el catálogo del $\mathrm{ME}^{11}$ como "adorno de oro"12.

En los recintos contiguos, 2 y 3 del sector 3 de Doncellas, se encontraron, además, piedras canteadas en proceso de trabajo; una de ellas tenía líneas curvas y paralelas pintadas en rojo en estilo similar al de las pinturas en la pared del Abrigo Choq' $\mathrm{e}^{13}$ que podrían ser un boceto de los sitios de cultivo y acequias cercanas. Es decir, esta capacocha formada con vasijas Puna Tricolor, sintoniza con el canteado de piedras ipara la escalera que se abre a una plaza sobre el sitio (estructura escalonada, usnu)? ¿para los muros de contención de los andenes de cultivo (pata) y acequias (larca)?, con los dibujos ¿esquemas de campos de cultivo (chacra)? en la pared del abrigo Choq ${ }^{\prime} \mathrm{e}^{14} \mathrm{y}$ con los terrenos ganados para cultivo de papas en ese sector de la puna ${ }^{15}$.

En 2003 propuse que los cuyos exiliados por Pachacutec tras una fallida rebelión, acompañados por los pacajes aliados del Inca, fuesen los constructores de ese centro ceremonial de modestas dimensiones a orillas del río Rachaite. Hasta ahora no hay evidencia de otra posibilidad, y la sincronía que propongo se articula a partir de datos locales. Por otra parte, hay vasijas que representan personas en distintos estilos andinos. La ropa puede estar pintada, o al personaje cuando está desnudo tal vez se lo vistiese en ocasión de una celebración. Faltaría precisar si fue un mismo personaje a lo largo del espacio y el tiempo andinos, o no ${ }^{16}$.

En el lapso entre las campañas de Eduardo Casanova en los '40, y de Alfaro y Suetta en los '70, Marta Ottonello excavó en Doncellas / Rachaite en las oquedades de los farallones de toba dentro de las cuales se encuentran las que

${ }^{11}$ Museo Etnográfico "Juan B.Ambrosetti”, Buenos Aires.

${ }^{12}$ HAEDO, P. G., Libreta de viaje a Doncellas. Ms., 1941, f. 28v.

${ }^{13}$ ALFARO, 1988, p. 39.

14 "Cchoque: Papas, comida ordinaria de los indios, es vocablo de los Pacases", BERTONIO, L., Vocabulario de la lengua aymara, Leipzig [1612] 1879. Los pacajes habitaban al sur del lago Titicaca; fueron con Topa Inca Yupanqui a la conquista del Sur y vestían uncu amarillo, representados en pinturas rupestres de la puna de Jujuy. GENTILE LAFAILLE, M. E., "Objetos prehispánicos legados en testamentos de indios (gobernación de Tucumán, 1608 y 1619)", en Revista Aquitas (Valladolid), 2 (2012a) 9-43. Junto a los dibujos, en la pared del abrigo Choqu'e había un personaje pintado con pocos trazos amarillos; el pequeño sector donde estaba se desprendió, cayó y se deshizo por el golpe, sin darme tiempo a tomar una foto. Los pacaje se reconocían por sus uncu color amarillo y su alfarería, de la que se hallaron algunos tiestos en Doncellas / Rachaite.

${ }^{15}$ ALFARO y SUETTA, 1976, p. 25, fig.25; GENTILE, 2003, p. 220, fig. 3.

${ }^{16}$ GENTILE, 2003, p. 234, fig. 14. 
llamó casas-tumba ${ }^{17}$, las chulpas que contenían los yacimientos (sensu Casanova) $)^{18}$, en la base de esos acantilados de unos diez metros de alto. Describió algunas alfarerías, sin otros aportes al tema de este ensayo.

Los farallones, donde se llevaron a cabo el grueso de las excavaciones por el equipo de Casanova y luego por Ottonello, rodean una planicie, cortada a lo largo por una cárcava de unos $2 \mathrm{~m}$ de profundidad en algunos puntos ${ }^{19}$, donde están los recintos que excavarán Alfaro y Suetta a partir de 1973. En uno de dichos recintos se halló el conjunto de vasijas que vengo de describir.

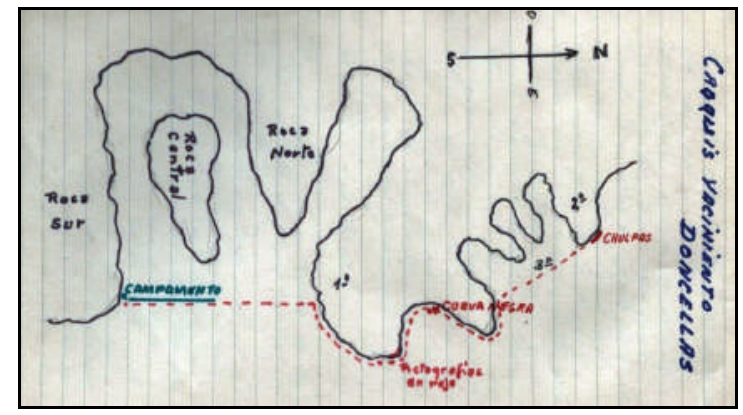

Figura 3. Pablo G. Haedo, Libreta de viaje a Doncellas. Copia electrónica facilitada por M.L. Fuchs. "Croquis yacimiento Doncellas", f.6r.. Coincide con los mapas del Instituto Geográfico Militar y la foto satelital en Google Earth, río Rachaite, 2019.

Respecto de la otra capacocha en Doncellas / Rachaite, los datos surgieron de un documento cuya copia electrónica se distribuyó informalmente hace unos años ${ }^{20}$; se trata de la "Libreta de viaje a Doncellas" de Pablo G. Haedo,

${ }^{17}$ OTTONELLO DE GARCIA REINOSO, M., "Instalación, economía y cambio cultural en el sitio tardío de Agua Caliente de Rachaite", en Publicación de la Dirección de Antropología (Jujuy), 1 (1973) 23-68.

${ }^{18}$ E. Casanova publicó dos trabajos con materiales de Doncellas: CASANOVA, E., "Comunicación acerca del yacimiento de Doncellas", en Boletín de la Sociedad Argentina de Antropología (Buenos Aires), 5-6 (1943) 80-81. CASANOVA, E., "Una estólica de la puna jujeña", en Revista Relaciones de la Sociedad Argentina de Antropología (Buenos Aires), IV (1944) 115-132. Mucho después, en la revista dirigida por Alfaro, publicó la versión libre de una de las figuras de la escena pintada en la "cueva del Hechicero". CASANOVA, E., "Una significativa pictografía de la puna jujeña", en Revista Antiquitas (Buenos Aires), V (1967) 1-3. Luego Alfaro publicó, sin mencionar origen, el dibujo que estaba en la Libreta de viaje a Doncellas, una de cuyas copias le enviara el mismo Haedo a Buenos Aires. ALFARO, L.C., "Arte rupestre en la cuenca del rio Doncellas (Provincia de Jujuy)", en Revista Relaciones de la Sociedad Argentina de Antropología, (Buenos Aires) XII (1978) 123-146.

${ }^{19}$ Llamado Rio Antiguo en ALFARO, 1988, p. 109.

${ }^{20}$ Agradezco a M.L. Fuchs la copia digital de esta libreta. Un avance en GENTILE, M.E., "Dos comentarios a la libreta de viaje a Doncellas de Pablo G. Haedo (1942?)", en Libro de Resumenes XX Congreso Nacional de Arqueología Argentina (Córdoba), (2019a) 733-734. 
ayudante técnico de Eduardo Casanova en la campaña a la puna de Jujuy en diciembre de 1941 o 1942. Su ubicación fue indicada ampliamente -algún punto por fuera de las chulpas de los farallones del costado norte de lo que él llamó Roca Central ${ }^{21}$; señaló el contenido de las vasijas, dibujó sus perfiles y su ubicación en planta formando casi una rueda. Dichas siluetas corresponden a alfarerías de Morohuasi, Quilmes, Molinos, Pampa Grande, Pucará de Tilcara, La Paya y Yavi $^{22}$. De la vasija número 1 hay foto de otra de perfil similar hallada en el R1del sector 1, “... pequeño jarro con as vertical de cerámica tosca, pero de buena forma" "23; no hay datos sobre su contenido, pero en ese recinto hubo por lo menos "dos párvulos en urna".

Por su parte, el catálogo de la Colección Doncellas en el ME dice que el Yacimiento LVIII estaba formado por: un recipiente de media calabaza pirograbada, un recipiente entero de calabaza pirograbada, un cuchillón de madera, un vasito [chato], un huso con tortero de madera y un mango de arma. Ante esta disparidad ${ }^{24}$, ya que hasta donde pude indagar no hay ningún Yacimiento 58 en números arábigos, sigo las anotaciones de Haedo y dejo abierta la posibilidad de algún cambio a futuro ante otras evidencias.

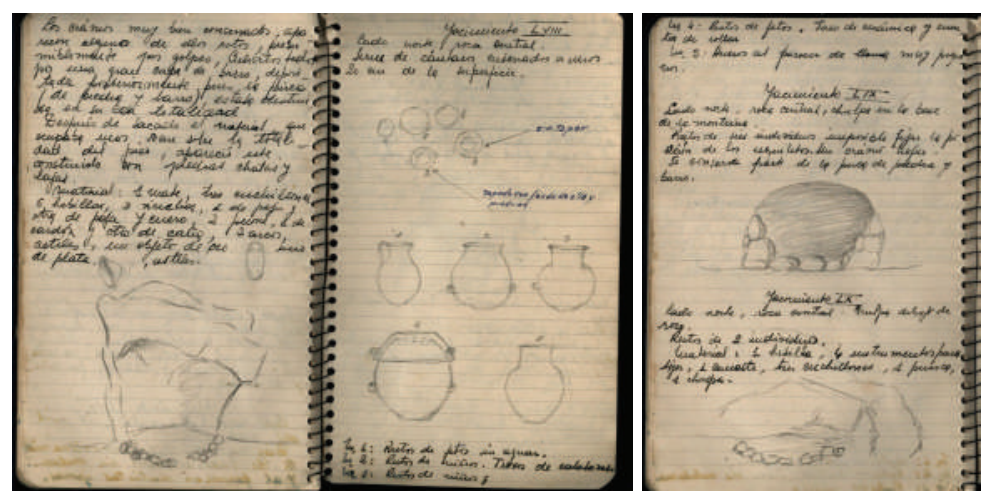

Figura 4. Pablo G. Haedo, Libreta de viaje a Doncellas. Copia electrónica facilitada por M.L. Fuchs. La letra es de la estudiante de Historia y los dibujos a lápiz son de Haedo (f.1r). De izquierda a derecha: f.28v: chapa de oro para ser cosida a una tela y campanilla de plata del yacimiento $L V I I$, sin medidas. F.29r-v: perfil y contenido de las vasijas del "Yacimiento LVIII. Lado norte, roca central. / Series de cántaros enterrados a unos. / $20 \mathrm{~cm}$ de la

${ }^{21}$ La Peña Fiera de ALFARO, 1988, p.109.

22 BREGANTE, O., Ensayo de clasificación de la cerámica del Noroeste argentino, Buenos Aires 1926, figs. 4, 20, 32, 184, 224 y 231. SERRANO, A., Manual de la cerámica indígena, Córdoba 1966, figs.25 y 28.

${ }^{23}$ ALFARO de LANZONE, 1988, p. 33.

${ }^{24}$ Las vasijas debieron romperse al sacarlas, razón por las que Casanova no las llevó al Museo ya que no recogía alfarerías rotas ni tiestos (Alfaro, com. pers.). 
superficie. $/ N^{\circ} 1$ : Restos de fetos sin ajuar. / $N^{\circ} 2$ : Restos de niños. Trozos de calabazas. $/ N^{\circ} 3$ : Restos de niños [un signo] / $N^{\circ} 4$ : Restos de fetos. Vaso de cerámica y cuentas de collar / $N^{\circ} 5$ : Huesos al parecer de llamas muy pequeños".

Esta capacocha, aun en su sencillez, se ajusta con datos del mismo sitio arqueológico, y dos datos coloniales, tempranos para la región. Los primeros corresponden a alfarería tardía; una de ellas se caracteriza por tener asas verticales abiertas, y su dispersión excede la puna ${ }^{25}$. Lo mismo respecto de la alfarería estilo Inca Pacajes y los hulti. Es decir, la presencia de alfarería de varios estilos tardíos en Doncellas / Rachaite no es algo extraordinario. Uno de los datos coloniales (1567) es la ruta para sacar los metales de Potosí a un puerto en la costa de la actual provincia de Buenos Aires. La ruta que partía de Potosí hacia el sur tenía cuatro posibles ramales; el que iba por la puna seguía el camino incaico bordeando las salinas, aprovechando aguadas y tambos ${ }^{26}$.

El otro dato colonial es la Relación de Pedro Sotelo Narváez (1582), alcalde de Santiago del Estero quien decía que los habitantes del valle de Calchaquí y los de la puna de Caxabindo hablaban unos la lengua de los otros ${ }^{27}$. Una de las razones de esta fluída comunicación bien podría haber sido el abastecimiento de sal, por parte de los de Calchaquí y otros grupos de otros sitios de la puna, en las salinas de Casabindo o Salinas Grandes de Guayatayoc, en explotación industrial hasta hoy. Hay caminos antiguos ${ }^{28}$.

En otras palabras, si se acuerda identificar a los grupos prehispánicos que habitaron el área andina argentina según sus estilos alfareros, propongo que lo que indica el dibujo de Haedo es que el Yacimiento LVIII fue el aspecto formal de una alianza entre cuatro grupos de la puna y del valle Calchaquí con la mediación de un oráculo que avalará la fidelidad entre todos ellos, es decir, una capacocha. Esos grupos podrían formase así: Morohuasi, puna de la actual provincia de Salta; Quilmes, Molinos, Pampa Grande y La Paya,

${ }^{25}$ ALFARO, L.C., y GENTILE, M.G., "Un nuevo tipo de asa en la cerámica del Noroeste argentino", en Revista Relaciones de la Sociedad Argentina de Antropología (Buenos Aires), XIV (1) (1980) 41-47.

${ }^{26}$ MATIENZO, J. de, Gobierno del Perú, Lima [1567] 1967, p.280. BOMAN, E., Antiquités de la region andine de la Repúblique Argentine, Paris 1908. GENTILE, M.E., "Evidencias e hipótesis sobre los atacamas en la puna de Jujuy y quebrada de Humahuaca", en Journal de la Société des Américanistes (Paris), 74 (1988) 87-103. GENTILE, 2003, p. 256, nota 3.

${ }^{27}$ GENTILE LAFAILLE, M. E., "Geografía y política. La gobernación de Tucumán en 1582, según la Relación de Pedro Sotelo Narváez", en Anuario Jurídico y Económico Escurialense (San Lorenzo del Escorial), XLV (2012b) 602.

${ }^{28}$ BOMAN, E., 1908, Carte Archéologique. RAFFINO, R.A., 1982. GENTILE, M.E., "El camino de Matienzo por la puna de Jujuy - Una hipótesis de trabajo", en Anales de Arqueología y Etnología (Mendoza), 38-40 (1983-1985) 159-181. 
valle de Calchaqui; Pucará de Tilcara, valle de Humahuaca; y Yavi, puna de la actual provincia de Jujuy.

Propongo, asimismo, que dicha fidelidad tuvo que ver con transitar entre el valle y la puna, atravesando territorios ajenos, sin agredirse unos a otros, y que podrían reconocerse entre ellos por viajar en determinada época del año por cierta ruta, llevando regalos, etcétera, además de los colores y diseños en la ropa. En cuanto a la elección del lugar para llevar a cabo ese acuerdo, el sitio Doncellas / Rachaite contó con elementos arquitectónicos indicativos de una funcionalidad ritual como los monolitos (huanca) y la estructura escalonada (usnu), además de objetos como los vasos de plata dorada, placas y collares, y la máscara de cuero pintada de rojo hallada en la Cueva del Hechicero, entre otros. Ubico cronológicamente la capacocha excavada por Alfaro y Suetta en el R3 de Doncellas / Rachaite, por ahora, ampliamente, durante el gobierno de Pachacutec, como lo propuse en 1985 y 2003.

En cuanto a la hallada al pie de uno de los farallones por Pablo G. Haedo, con los datos disponibles hasta ahora no me es posible precisar si fue inmediatamente anterior o posterior a la fundación del Tahuantinsuyu por Pachacutec, dada su dependencia de los estilos alfareros de las vasijas, a que la búsqueda de sal fue, casi con seguridad, anterior a la presencia incaica en la zona, y a que parte del tránsito norte-sur y viceversa tenía dos caminos alternativos y paralelos: por la puna y por el valle de Humahuaca.

\section{CERRO ACONCAGUA, ANDES DE MENDOZA (c.5300 m.s.n.m)}

La capacocha incaica del cerro Aconcagua fue hallada en 1985 en el cono adventicio del volcán. La estatuilla femenina, tallada en mullu, que se encontró años antes en Confluencia ${ }^{29}$ indicaba la ruta pero también que el conjunto había colapsado naturalmente y sus piezas se habían dispersado rodando cerro abajo cuando el deshielo removió el terreno en "el techo de los Andes".

Los resultados de los estudios técnicos fueron muy interesantes; además, se confirmó lo que decía Joan de Santa Cruz Pachacuti, respecto de que eran niños de corta edad y sin tacha los que los Incas ofrecían en los nevados ${ }^{30}$. El

${ }^{29}$ SCHOBINGER, J.; AMPUERO, M., y GUERCIO, E., "Descripción de las estatuillas que conformaban el ajuar acompañante del fardo funerario hallado en el cerro Aconcagua (Provincia de Mendoza)", en Relaciones de la Sociedad Argentina de Antropología (Buenos Aires), XVI (1984-1985) 175-189.

30 SANTA CRUZ PACHACUTI YAMQUI SALCAMAYGUA, J. de, Relación de antiguedades deste reyno del Piru, [1613?], f.14 v. 
niño estaba recostado contra una pared de piedra (pirca) semicircular; al lado había otra pirca similar que, hasta donde sé, no se excavó. En particular, estaba literalmente pintado por dentro y por fuera de color rojo, color que predominó también en su atuendo ${ }^{31}$ y en la geología del sitio donde se lo hallós ${ }^{32}$. Este color también predomina en el atuendo de El Niño de Llullaillaco.

El enlace entre Aconcagua y Llullaillaco son estos niños acompañados de una comitiva de estatuillas de hombres y camélidos donde destaca el color rojo; la variante es el penacho de plumas: negras en el primero, blancas en el segundo. Mi propuesta de 1996 respecto del significado de las plumas negras tendría que ser revisada. También en mi ensayo de 1996 articulé, hasta donde me fue posible, los datos técnicos con los prehispánicos y coloniales. En el lapso hasta hoy se precisaron algunos términos usados en aquella oportunidad; respecto de la expresión "momia", hoy describe mejor ese hallazgo decir cuerpo desecado naturalmente, o similar, ya que el mismo estaba intacto. También "figuritas" por "estatuillas", expresión ésta última que remite a la manufactura.

La interpretación de los diseños de dos de los uncu -tipos A y B, que vestían la estatuilla de oro y la de mullu- fue ampliada con Llullaillaco respecto del rango y la edad de cada uno de esos hombres. Hoy también se sabe que el hombre que vestía el uncu monocromo color verde oscuro, representado en la estatuilla de plata, era el jefe local con quien el Inca estaba realizando la alianza. También la influencia de la cultura Moche en Inca a través de Chimú, notable en la ropa y objetos usados por los participantes en la capacocha de Aconcagua se revalidó y amplió en Llullaillaco. Los colores rojo y amarillo resultaron ser comunes a ambas ceremonias. El cuadro de cronología relativa de la presencia incaica en este sector de los Andes se pudo, asimismo, reafirmar y ampliar.

En 1996 cité como referencias los hallazgos de Salinas Grandes (puna de Jujuy) y El Pichao (valle de Calchaquí) ${ }^{33}$. En mi opinión actual, la primera ya no reúne las condiciones para considerarla como capacocha incaica. En cuanto a la segunda referencia, la vasija que contiene el niño es contemporánea con la presencia Inca en la región pero falta el camélido; podría haber sido un niño nacido con labio leporino, de quien se creía que era hijo de Yllapa, el Rayo ${ }^{34}$.

${ }^{31}$ BÁRCENA, J.R., "Pigmentos en el ritual funerario de la momia del Cerro Aconcagua (Provincia de Mendoza, República Argentina)", en Revista Xama (Mendoza), 2 (1989) 61-116.

32 GENTILE, 1996, p. 55.

33 GENTILE, 1996, p. 73, nota 44.

${ }^{34}$ GUAMAN POMA DE AYALA, P., El primer Nveva Coronica i Bven Gobierno conpvesto por don... c. 1615 , f. 885 . En el siglo XVI esa deformación congénita no tenía solución; el niño del relato vivió un mes. 


\section{VOLCÁN LLULLAILLACO, PUNA DE SALTA (c. 6739 m.s.n.m)}

En 1999 se hallaron casi en la cima de este volcán tres capacochacuna ${ }^{35}$. Como iteraban el aspecto formal de la de Aconcagua, pude determinar los rasgos mínimos en las dos que venimos de ver en Doncellas / Rachaite, confirmando lo dicho en mi publicación de 2003.

En Llullaillaco, alrededor de ellas se rescataron diez estatuillas antropomorfas masculinas, doce femeninas, seis camélidos machos (metal) y nueve camélidos hembras (mullu). Los animalitos estaban alrededor de El Niño, al igual que en Aconcagua. Como parte del Proyecto "Estudio ...", en el laboratorio del MAAM pude observar formas y colores de la ropa que vestían, y las características de las manufacturas. Tras reconstruir la estratigrafía, y cruzando esos datos con textos coloniales propuse agrupaciones de estatuillas que representaban personas de distintas edades, rangos y funciones durante la realización de la ceremonia.

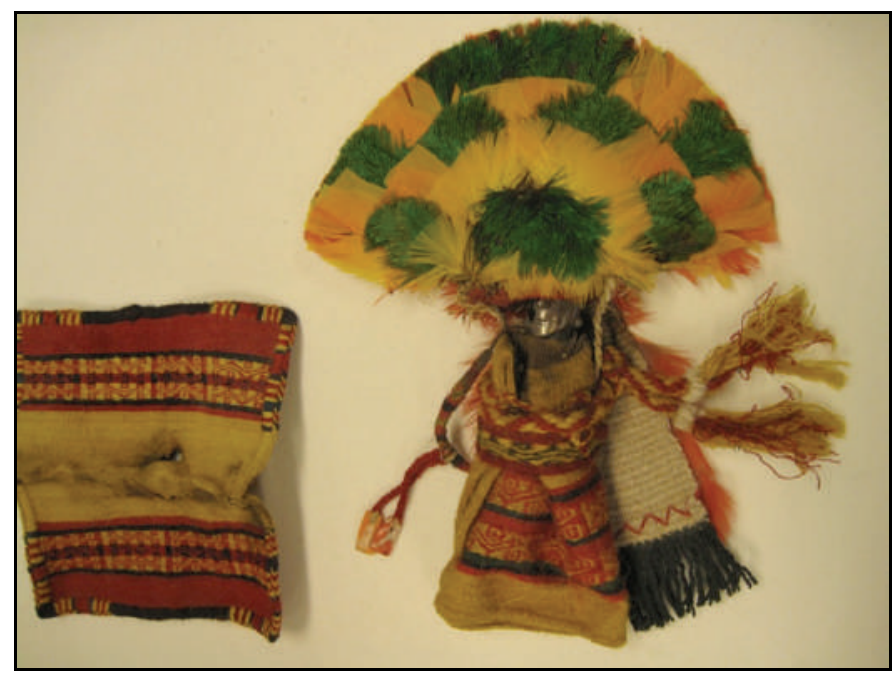

Figura 5. Capacochacuna de Llullaillaco. Estatuilla femenina de plata LL-99-015, representa una de las acllas de la comitiva de La Niña. La lliclla, desplegada a su lado, muestra los rastros de una de las descargas eléctricas sufridas en el siglo XIX, durante una erupción del volcán. Propiedad del MAAM. Foto de M.E. Gentile.

${ }^{35}$ REINHARD, J., "A 6,700 metros niños incas sacrificados quedaron congelados en el tiempo", en Revista National Geographic (Washington), (1999) 36-55. CERUTI, M.C., Llullaillaco. Sacrificios y ofrendas en un santuario inca de alta montaña, Salta 2003. MUSEO DE ARQUEOLOGÍA DE ALTA MONTAÑA, SALTA, www.maam.gob.ar 


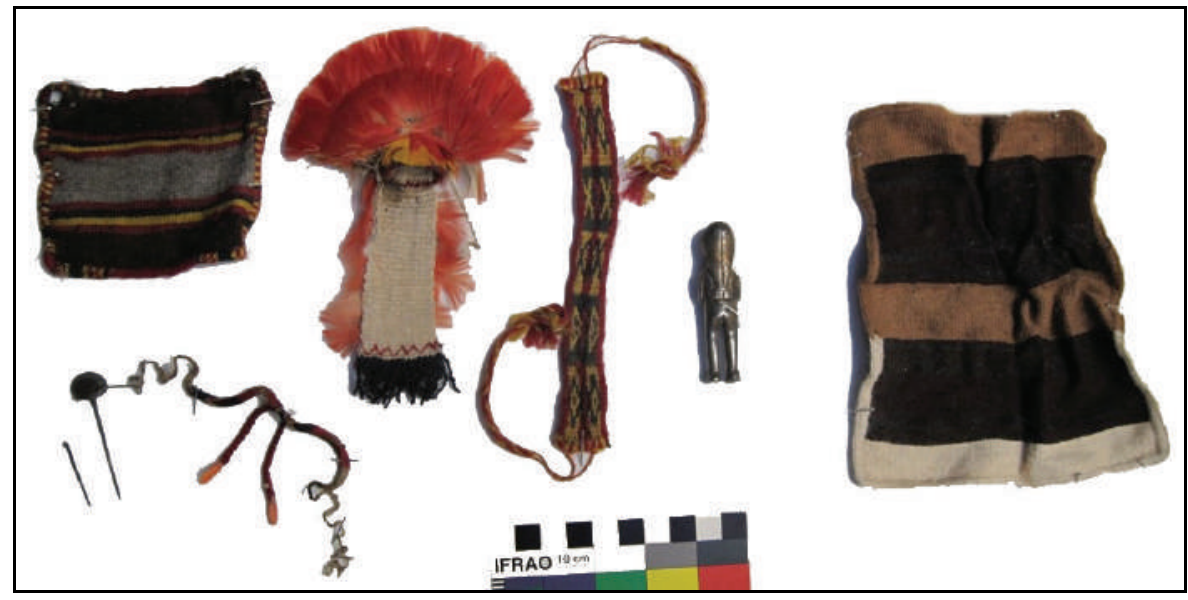

Figura 6. Capacochacuna de Llullaillaco. Estatuilla femenina de plata LL-99-014. Elementos del vestuario, de izquierda a derecha: manta desplegada, con la cabeza del alfiler que la sostenía prendida en la tela, en tanto que el resto del alfiler se ve a la izquierda junto al otro alfiler que no destruyó la ráfaga eléctrica, y que es uno de los dos que sostenía el vestido y al cual están sujetos el tejido tubular y las placas zumbadoras. Arriba, diadema e ínfula recamadas de plumas y junto a ellas la faja que sujetaba el vestido. La estatuilla está de espaldas, el cabello está sujeto con una hebilla y a su lado, desplegado, se encuentra el vestido. Propiedad del MAAM. Foto de M.E. Gentile.

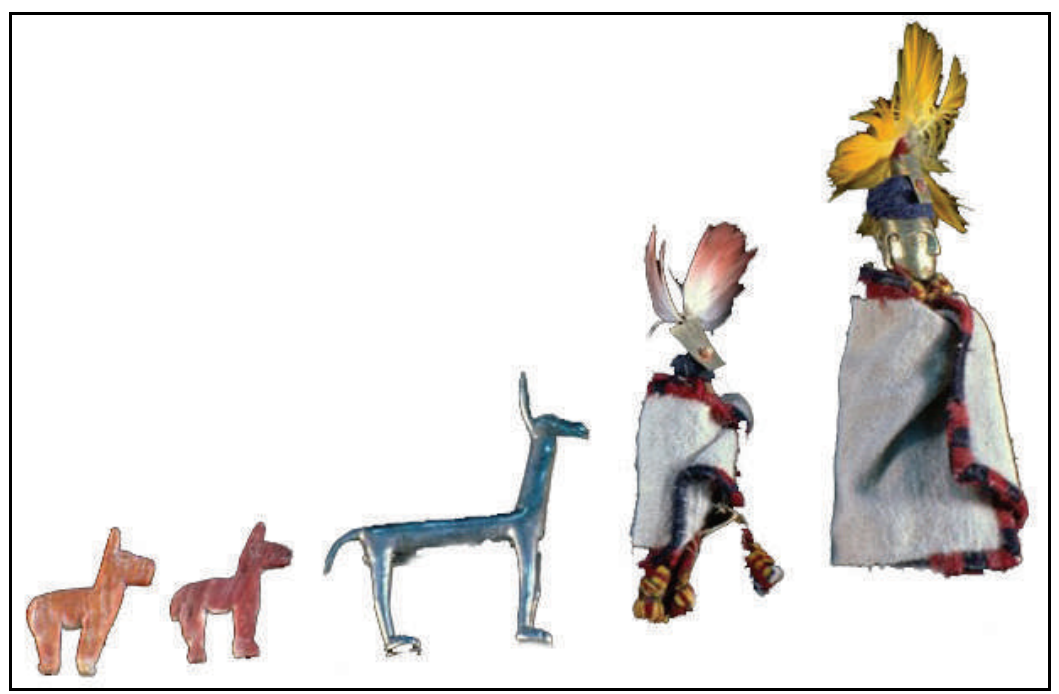

Figura 7. Capacochacuna de Llullaillaco. Estatuillas antropomorfas masculinas seguidas de una llama macho de plata y dos hembras de mullu. Encabeza la fila la de oro (LL-99-089) y le sigue la de mullu (LL-99-090). Museo de Arqueología de Alta Montaña, Salta. Propiedad del MAAM. Foto J. Reinhard. 


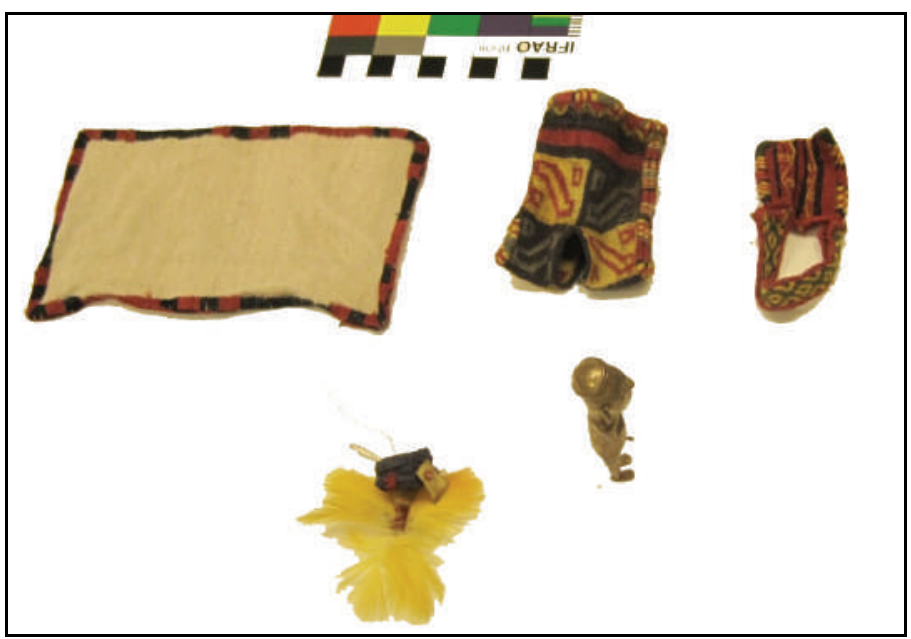

Figura 8. Capacochacuna de Llullaillaco. Estatuilla masculina de oro LL-99-089. Desplegada, la yacolla; siguen el uncu y la chuspa para hoja de coca. Abajo, la huasca arrollada que tenía en la cabeza a la que están prendidos el penacho de plumas amarillas y la placa de oro con chaquira de mullu. Sería el representante del Inca. Museo de Arqueología de Alta Montaña, Salta. Propiedad del MAAM. Foto de M.E. Gentile.

La etapa siguiente del Proyecto incluye las estatuillas que aún no fueron desarropadas y los estudios técnicos, que serán el núcleo de estudios comparativos y su articulación con lo que se sabe hasta ahora a fin reajustar, o no, las propuestas publicadas. Lo que sigue es un resumen de los temas tratados entre 2017 y 2020 , las líneas generales de esta ceremonia incaica, participantes, producción, función y proyección desde que Pachacutec la instauró.

En 1567, Juan Diez de Betanzos ${ }^{36}$ dio noticia de "escuadroncitos" formados con miniaturas de personas, ubicados alrededor del usno en la plaza del Cusco cuando se refundó la ciudad como capital del Tahuantinsuyu. Años después, en su recopilación de experiencias como extirpador de idolatrías, Cristóbal de Albornoz decía que a las huacas principales, además de vasos de metal y ropa fina, se les ofrecían estatuillas de oro, plata y Spondylus ${ }^{37}$, tal como se hallaron en Aconcagua y Llullaillaco. Las estatuillas talladas en calcita procedentes de las excavaciones en la plaza frente a los muros de Sacsayhuaman ${ }^{38}$

${ }^{36}$ FBM - Fundación Bartolomé March Servera. Palma de Mallorca, España, 77-3, Betanzos, Juan de Betanços, Suma y narracion. De los Yngas que los yndios nombraron... [1551], Cap. XI.

${ }^{37}$ ALBORNOZ, C. de, en DUVIOLS, P., “Albornoz y el espacio ritual andino prehispánico”, en Revista Andina (Cusco), 2 (1) (1984) 169-222.

38 VALENCIA ZEGARRA, A., "Las microesculturas de Saqsaywaman", en Revista Saqsaywaman (Cusco), 1 (1970) 159-177. Hay microesculturas de objetos, que en Aconcagua y Llullaillaco también están miniaturizados. 
-formalmente similares y contemporáneas a las de metal y mullo halladas en Aconcagua y Llullaillaco- quedan incluidas en el tiempo del Tahuantinsuyu.

En otro orden, las estatuillas podrían no haber sido retratos personales pero es notable que rostros y cuerpos son distintos entre sí, aun en la similitud de la manufactura. La buena conservación de la ropa miniatura que vestían facilitó las indagaciones acerca de significados de forma y color, uso y función de estas prendas.

\subsection{Vestuario femenino}

Las mujeres miniatura que acompañan las capacochacuna femeninas de Llullaillaco visten prendas comunes a las de la elite incaica: vestido $(a c s u)$ y manta (lliclla) prendidos con alfileres de metal (tupu), y el vestido ceñido con una faja (chumpi). Las de metal tienen el cabello sujeto con una hebilla, en tanto que las otras, a veces, no.

En ocasión de participar en esta ceremonia llevan, además, prendas litúrgicas. El tejido tubular sujeto por los tupu, y que cae por delante del $a c s u$, representa un ofidio, el machacuay, asociado a un juego oracular, ayllar el machacuay, mediante el cual el Inca anexaba al Tahuantinsuyu territorios y gente sin confrontar bélicamente $^{39}$, y trasladaba poblaciones (mitmacuna), por premio o castigo.

El dibujo de rombos del tejido tubular se reprodujo en cerámica en la guía vertical de los aríbalos cusqueños, síntesis de una mujer lujosamente vestida.

Otras prendas litúrgicas son diadema e ínfula, que en su origen son prendas masculinas pero que aquí representan una cuota de autoridad adquirida por algunas mujeres mediante complejas reciprocidades derivadas de una guerra de conquista durante la expansión del Tahuantinsuyu ${ }^{40}$.

Algunas mujeres de este conjunto tienen los tres colores mas visibles del arco iris (cuychi) tejidos en su lliclla; este diseño y el de las riadas (amaru) tejidas en algunos $a c s u$, indican su procedencia del territorio al Este del volcán, es decir, los valles y las tierras bajas, región con la que el Inca está celebrando la

39 GENTILE, M. E., "El Amaru como emblema de los Incas del Cusco (siglos XVIXVII)", en Revista El Futuro del Pasado (Salamanca), 8 (2017b) 297-327. GENTILE, M.E., "Placas zumbadoras y sogas sibilantes asociadas a las capacochacuna del volcán Llullaillaco", en Revista El Futuro del Pasado (Salamanca), 9 (2018b) 15-42.

${ }^{40}$ GENTILE LAFAILLE, 2019b. 
alianza $^{41}$. Las mujeres elegidas (acllacuna), tanto si vivían en el Cusco como en los edificios especialmente destinados para ellas en los territorios aliados, se reconocían en el color de su ropa. En Llullaillaco tenemos tres de las cuatro clases de mujeres elegidas porque las que vestían ropa de color blanco, o por lo menos de color claro (yurac aclla) no salían de Coricancha, de ahí la comparación con las monjas de clausura ${ }^{42}$.

\subsection{Vestuario masculino}

En todas las manufacturas, -calcita, metal, mullu-, las estatuillas masculinas solo llevan puesto un gorro (chucu). Excepto las primeras, que se hallaron desnudas, en las otras la ropa fue tejida aparte y es la común a los varones andinos: manta (yacolla), camiseta (uncu) y bolsa para hojas de coca (chuspa). En esto no hay indicios de que ninguno proceda de las tierras bajas, aunque sí son originarios de allí hoja de coca y plumas.

Llevan también objetos de uso ceremonial. La soga (huasca), con un extremo rojo, va arrollada sobre el gorro o envuelve la yacolla e indica, junto con las orejas agrandadas y el cabello corto, que se trata de un orejón habitante del Cusco que participó en la citua, ceremonia anual mediante la cual se echaban las enfermedades de la ciudad.

A primera vista las estatuillas masculinas se distinguen por un penacho de plumas sobre la cabeza: amarillas en las que visten el uncu signo "Alianza entre suyus / ayllus pactada bajo la amenaza de un ataque con aluviones / incendios"; tienen sujeta al mismo una placa trapezoidal de oro y visten yacolla de color blanco natural. En las que visten uncu signo "Territorialidad discontínua / Territorios ganados para cultivos de maíz" el penacho de plumas puede ser negro, amarillo o rojo; no llevan placa de metal y la yacolla es color marrón oscuro.

La placa de metal está perforada en el centro del tercio superior por donde pasa un cordel de fibra vegetal que sujeta una mostacilla (chaquira) de mullu o de turquesa, según. En un trabajo previo propuse que los hombres que visten el uncu "alianza ..." y llevan placa de metal forman parte de un grupo cercano al Inca, en tanto que los que visten el uncu "territorialidad...", sin placa de metal,

\footnotetext{
${ }^{41}$ GENTILE LAFAILLE, M.E., “Arte, religión y política: etnohistoria de algunas prendas litúrgicas incaicas procedentes de Llullaillaco", en prensa 2020.

${ }^{42}$ GENTILE LAFAILLE, M.E., "Mamacuna y monjas de clausura. Notas para unos derroteros institucionales andinos (siglos XV-XVI)", en Simposium (San Lorenzo del Escorial), XIX Edición (2011b) 1076-1092. GENTILE LAFAILLE, 2020.
} 
fueron parte de un grupo menos compacto, que tanto podrían ser familiares como servidores forasteros especializados (yanacuna) del Inca, de la Coya o del Sol.

De entre todos, uno de los hombres viste uncu rojo, sin dibujos (tocapu $)^{43}$. Por su ubicación en Llullaillaco junto al representante del Inca, por llevar placa de oro con chaquira de mullu y por documentación colonial regional, se sabe que se trata de un jefe local con quien se concertó la alianza en la cima del volcán; previamente, este personaje había participado en la celebración de un itu ${ }^{44}$. Esto me permite plantear que los niños pintados / vestidos de rojo, en Aconcagua y Llullaillaco, podría corresponder a la celebración de itu, rogativa por una pestilencia o guerra importante dado que se realizó en sitios fuera del Cusco.

Por otro lado, la chaquira de turquesa tiene que ver con el origen de la capacocha en una costumbre de los collas, cuya huaca oracular (Copacabana) era un ídolo tallado en esa piedra. Y de entre el grupo de hombres ubicados junto al Niño, dos tienen esa mostacilla sujetando la placa de metal y estuvieron relacionados con la interpretación del oráculo ${ }^{45}$. Respecto de la chaquira de mullu, hasta ahora, no encontré una explicación validada en documentación colonial.

En cuanto a la edad, tanto en Aconcagua como en Llullaillaco, el uncu "territorialidad ..." lo visten hombres de menos de cuarenta años; pero la misma prenda con el diseño "alianza..." era propio de hombres de más edad. Es decir, los guerreros eran más jóvenes que los diplomáticos. En cuanto a la técnica de su realización, las estatuillas de los diplomáticos son de oro, laminadas, huecas, en tanto que las de los guerreros, sean de oro o mullu, son macizas.

En las de oro, tanto huecas como macizas, los personajes representados ya no llevan puestas las orejeras; esto podría indicar que su portador ya alcanzó el máximo de cierta jerarquía, política, religiosa, o ambas, indicado también por el bolo de hojas de coca en la mejilla (acullicu); también podría ser signo de respeto, como ir descalzo. Las de mullu, piezas realizadas por talla directa, tienen las orejas grandes y en alguna el hueco está indicado superficialmente, es decir, tampoco llevan puestas las orejeras.

Los hombres que llevaban una bolsa para hoja de coca (chuspa) con el diseño de cabezas cercenadas y apiladas -signo "guerra y escarmiento"- participaron en

\footnotetext{
${ }^{43}$ GENTILE, M.E., "Tocapu: unidad de sentido en el lenguaje gráfico andino", en Revista Espéculo (Madrid), 45 (2010) 1-25.

${ }^{44}$ GENTILE LAFAILLE, M.E., "Etnohistoria de una prenda incaica poco común: el uncu monocromo (área andina argentina)", en Revista Cruz del Sur (San Isidro, prov.de Buenos Aires), 33 (2019b) 11-92.

${ }^{45}$ GENTILE LAFAILLE, 2017a.
} 
una guerra en favor del Tahuantinsuyu y consiguieron trofeos de cabezas de enemigos, de ahi que el Inca les autorizara a chacchar hoja de coca ${ }^{46}$. No obstante, hombres y mujeres de las comitivas que acompañaron las capacochacuna van descalzos, tal como quienes iban a hablar con el Inca ${ }^{47}$. Las capacochacuna, en cambio, llevan calzados.

\subsection{Música, canto, recitado}

La celebración de la alianza era escenificada durante la marcha de la procesión que llevaba las capacochacuna desde el Coricancha, en el Cusco, hasta la cima del volcán. De esta manera, las poblaciones por las que pasaba se enteraban del suceso. La marcha se acompañaba con los silbos característicos del machacuay reproducidos mediante el girar de las huascas que llevaban los hombres y las placas zumbadoras que portaban las mujeres. Rumbo a Llullaillaco cantarían las victorias de Topa Inca Yupanqui ${ }^{48}$. Instrumentos musicales como pequeños tambores (tinya) y flautas de tubos escalonados (antara) no se hallaron en el sitio lo que permite pensar que regresaron al Cusco con quienes los tocaban, o que fueron incinerados en el lugar.

\subsection{Orden en el vestir de los atuendos.}

El trabajo en laboratorio, desarropar y volver a vestir las miniaturas, dejó en claro el orden en el que fue realizada dicha tarea; esto permitió discernir algunas diferencias personales respecto de quienes la llevaron a cabo, aunque las pautas en el vestir de las estatuillas fueron estrictas.

Tanto la manufactura de las estatuillas y su ropa como la preparación para presentarlas, fue un tipo de trabajo rotativo y obligatorio (mita) en el que intervinieron muchos artesanos especializados, entre otros: tejedores, orfebres, escultores, además de los proveedores de materia prima: pastores, recolectores de plumas, mineros y buzos pescadores ${ }^{49}$, hasta llegar estos elementos a manos de quienes debían vestir las estatuillas con determinada ropa y en un cierto orden.

${ }^{46}$ GENTILE LAFAILLE, M.E., "Iconología de un diseño incaico en Llullaillaco", en Revista Cruz del Sur (San Isidro, prov.de Buenos Aires), 26 (2017c) 127-179.

47 Los personajes grabados en el matecito de Pucarilla también están descalzos; esa ceremonia fue una capacocha de otro tipo del que estamos viendo en este ensayo. GENTILE, M.E., "El censo de los runa: datos y reflexiones sobre los incas en el Collasuyu" en Nueva Corónica (Lima), 2 (2013) 91-120.

${ }^{48}$ GENTILE, 2018b. GENTILE LAFAILLE, 2020.

${ }^{49}$ GENTILE LAFAILLE, M.E., 2017a. 


\subsection{Léxico de los elementos de vestuario}

Dado que la nomenclatura en lenguas indígenas para muchos de los elementos de vestuario no se recogió oportunamente, en ocasión de tener que completar las fichas correspondientes al Proyecto preparé un léxico abierto a partir del castellano, con la descripción de la ropa ${ }^{50}$.

\subsection{Creencias andinas y europeas acerca de los volcanes}

Para unos y otros el interior de estos cerros tan particulares estaba habitado. Las creencias andinas prehispánicas sobre algunos de sus ancestros que salieron de volcanes tuvieron su correlato en algunas creencias europeas medievales. Sin embargo, éstas últimas eran de signo opuesto, desemejantes, ya que los europeos creían que por los cráteres de los volcanes se entraba al Infierno, y que por allí también salían los demonios al mundo de los humanos ${ }^{51}$.

\subsection{Gráfica incaica / ¿lengua secreta de los Incas?}

El sistema de comunicación incaico se basó en diseños que hoy llamaríamos abstractos en contraposición con los figurativos que, en términos andinos, abarcarían la gráfica de las culturas Moche, Nasca, Chimú, etcétera, aunque algunos diseños estén, también expresado en términos actuales, estilizados. Forma y color estuvieron, durante el Tahuantinsuyu, ligados al uso y función. La siguiente tabla es parte del avance en el tema, a partir de las capacochacuna. Del uncu tipo C, color negro, solamente se tiene noticia en dibujo en alfarería y documentación colonial.

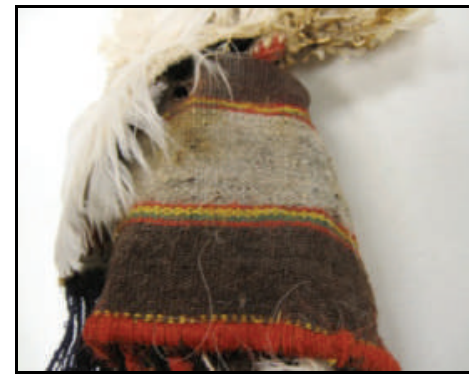

Manta femenina, lliclla Signo arco iris, cuychi

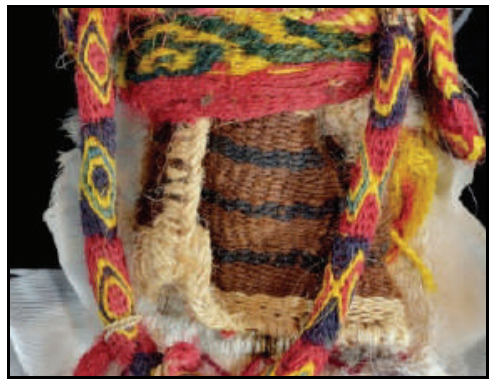

Vestido femenino, acsu Signo riadas, Amaru

${ }^{50}$ GENTILE LAFAILLE, M.E., 2017a.

${ }^{51}$ GENTILE LAFAILLE, M.E., "Vulcanismo y terremotos andinos. Alcance sociopolítico y religioso de algunas creencias en el siglo XVI", en Anuario Jurídico y Económico Escurialense (San Lorenzo del Escorial), LI (2018a) 501-520. 


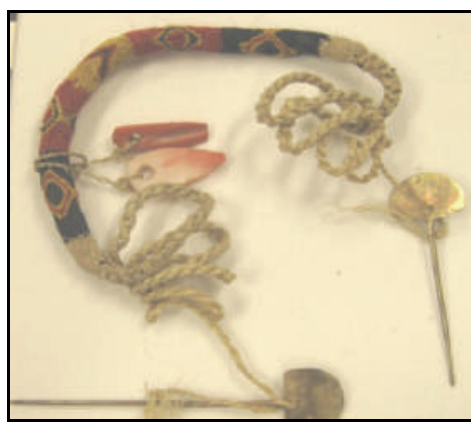

Tejido tubular prendido a la manta con dos alfileres, tupu

Signo boa, machacuay

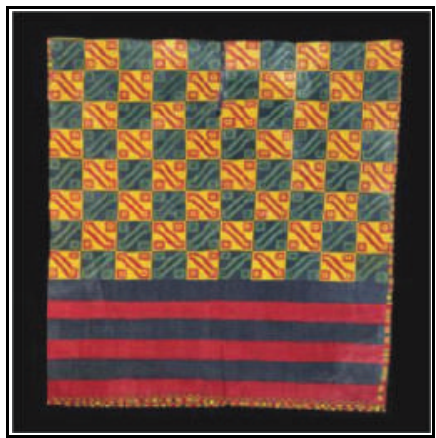

Uncu tipo B, signo "alianza entre suyus / ayllus pactada bajo la amenaza de un ataque con aluviones / incendios" (Gentile 1996, p. 62 y stes.; 2017c).

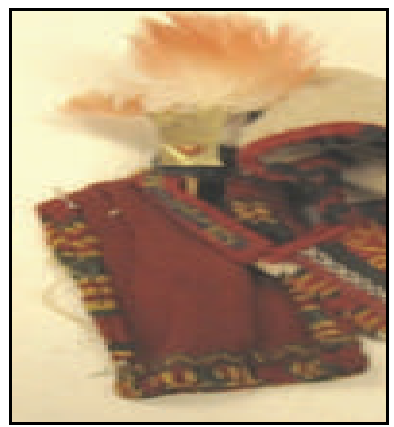

Uncu tipo D, color rojo, signo "participante en la rogativa Itu” (Gentile, 2017c).

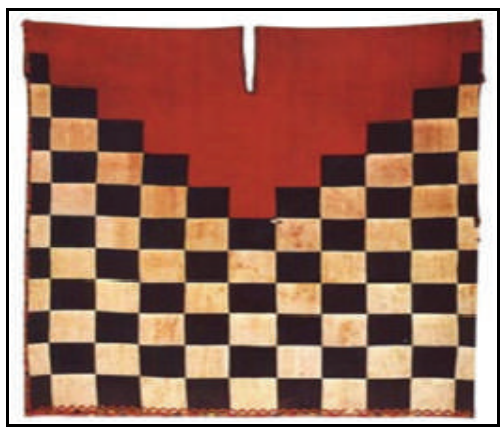

Uncu tipo A, signo Territorialidad discontínua, o territorios ganados para cultivos de maiz (Gentile 1996, p. 62 y stes.; 2017c).

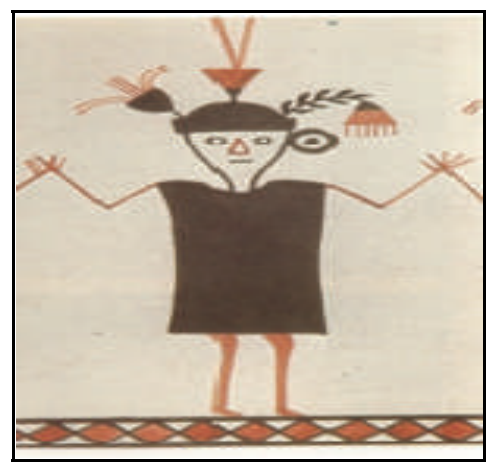

Uncu tipo C, color negro, signo "ingreso a la elite cusqueña” (Gentile, 2017c).

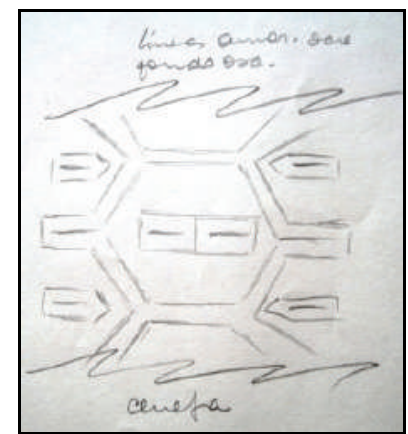

Signo "guerra y escarmiento" en chuspa para hoja de coca (Gentile 2017c)

Figura 9. Signos en mantas femeninas, vestidos, camisetas, bolsa para hoja de coca de las capacochacuna de Aconcagua y Llullaillaco. 


\section{CRONOLOGÍA RELATIVA}

A falta de fechados absolutos puntuales respecto de los temas vistos aqui con relación a las capacochacuna de Doncellas / Rachaite, Aconcagua y Llullaillaco, por ahora fecho relativamente las ceremonias en el R3 de Doncellas durante las conquistas de Topa Inca Yupanqui, cuando su padre, Pachacutec, todavía gobernaba y su hermano Amaro Topa Inca organizaba el calendario y la infraestructura agropecuaria; en cuanto a la capacocha descrita por Haedo, es probable que sea algo posterior.

Por su parte, Aconcagua y Llullaillaco pueden fecharse tras la conquista del Collao y Chimú -y sus artesanos especializados-, por Topa Inca Yupanqui. Es decir, Llullaillaco ajustó la cronología relativa que propuse para Aconcagua en 1994.

\section{BIBLIOGRAFÍA CITADA}

\section{Documentos en archivos}

- Biblioteca Nacional de España (BNE), Madrid. Mss. 3169

Papeles varios sobre los indios Incas, Huarochiris y otras antigüedades del Perú. http://bdh.bne.es/bnesearch/detalle/bdh0000087346

[Contiene: Cristóbal de Molina "el cusqueño", Juan Polo de Ondegardo, Francisco de Avila y Joan de Santa Cruz Pachacuti].

- Fundación Bartolomé March Servera (FBM), Palma de Mallorca, España. 77-3 Betanzos, Juan de Betanços, Suma y narracion. De los Yngas que los yndios nombraron... [1551].

\section{Publicaciones}

- ALBORNOZ, C. de, en DUVIOLS, P., "Albornoz y el espacio ritual andino prehispánico", en Revista Andina (Cusco), 2 (1), (1984) 169-222. http://www.revistaandinacbc.com/wp-content/uploads/2016/ra03/ra-03-198408.pdf

- ALFARO DE LANZONE, L. C., y SUETTA, J. M., "Nuevos aportes para el estudio del asentamiento humano en la puna de Jujuy. Revisión del Pucará de Rinconada", en Revista Antiquitas (Buenos Aires), X (1970) 1-10. https://racimo.usal.edu.ar/id/eprint/514 
- ALFARO de LANZONE, L. C., y SUETTA, J. M., "Excavaciones en la cuenca del río Doncellas", en Revista Antiquitas (Buenos Aires), XXIIXXIII (1976) 1-32. https://racimo.usal.edu.ar/id/eprint/547

- ALFARO, L.C., "Arte rupestre en la cuenca del rio Doncellas (Provincia de Jujuy)", en Revista Relaciones de la Sociedad Argentina de Antropología, (Buenos Aires) XII (1978) 123-146. http://www.saantropologia.com.ar//wpcontent/uploads/2015/01/Relaciones\%2012/08-Alfaro.pdf

- ALFARO, L. C., y GENTILE, M. E., "Un nuevo tipo de asa en la cerámica del Noroeste argentino", en Revista Relaciones de la Sociedad Argentina de Antropología (Buenos Aires), XIV (1) (1980) 41-47.

http://www.saantropologia.com.ar/textos/un-nuevo-tipo-de-asa-en-la-ceramicadel-no-argentino/

- ALFARO, L. C., "Materiales arqueológicos posthispánicos en la cuenca del río Doncellas, Prov.de Jujuy", en Revista Relaciones de la Sociedad Argentina de Antropología (Buenos Aires), XIV (2) (1981-1982) 81-83. http://www.saantropologia.com.ar/textos/materiales-posthispanicos-en-lacuenca-del-rio-doncellas-jujuy/

- ALFARO de LANZONE, L. C., Investigación en la cuenca del río Doncellas, Depto.Cochinoca, Pcia.de Jujuy. Reconstrucción de una cultura olvidada en la Puna Jujeña, Jujuy 1988.

- BÁRCENA, J. R., "Pigmentos en el ritual funerario de la momia del Cerro Aconcagua (Provincia de Mendoza, República Argentina)", en Revista Xama (Mendoza), 2 (1989) 61-116.

- BERTONIO, L., Vocabulario de la lengua aymara, Leipzig [1612] 1879. https://www.wdl.org/es/item/13776/view/1/1/https://www.wdl.org/es/item/ 13776/view/1/1/

- BOMAN, E., Antiquités de la region andine de la Repúblique Argentine, Paris 1908. https://archive.org.

- BOMAN, E., "Una momia de Salinas Grandes", en Anales de la Sociedad Cientifica Argentina (Buenos Aires), 85 (1918) 94-102. https://archive.org,

- BREGANTE, O., Ensayo de clasificación de la cerámica del Noroeste argentino, Buenos Aires, 1926. 
- CASANOVA, E., "Comunicación acerca del yacimiento de Doncellas", en Boletín de la Sociedad Argentina de Antropología (Buenos Aires), 5-6 (1943) 80-81. http://www.saantropologia.com.ar//wp-content/uploads/2014/ 11/Boletin-1943-5-6r.pdf.

- CASANOVA, E., "Una estólica de la puna jujeña", en Revista Relaciones de la Sociedad Argentina de Antropología (Buenos Aires), IV (1944) 115-132.http://www.saantropologia.com.ar/textos/una-estolica-de-la-punajujena/.

- CASANOVA, E., "Una significativa pictografía de la puna jujeña", en Revista Antiquitas (Buenos Aires), V (1967) 1-3. https://racimo.usal.edu.ar/ id/eprint/482.

- CERUTI, M.C., Llullaillaco. Sacrificios y ofrendas en un santuario inca de alta montaña, Salta 2003.

- FERNÁNDEZ BACA, J., Motivos de ornamentación de la cerámica Inca Cuzco, Lima 1973.

- FERNÁNDEZ BACA, J., Motivos de ornamentación de la cerámica Inca Cuzco II, Lima 1989.

- GENTILE LAFAILLE, M. E., "El camino de Matienzo por la puna de Jujuy Una hipótesis de trabajo", en Anales de Arqueología y Etnología (Mendoza), 38-40 (1983-1985) 159-181. http://naturalis.fcnym.unlp.edu.ar/id/20180627 015260

- GENTILE LAFAILlE, M. E., "Hulti - Acerca del uso de cierta alfarería Tiwanaku expansivo", en Revista Relaciones de la Sociedad Argentina de Antropología (Buenos Aires), XVI (1985) 205-220.

http://www.saantropologia.com.ar/textos/hulti-acerca-del-uso-de-ciertaalfareria-tiwanaku-expansivo/

- GENTILE LAFAILLE, M. E., "Evidencias e hipótesis sobre los atacamas en la puna de Jujuy y quebrada de Humahuaca", en Journal de la Société des Américanistes (Paris), 74 (1988) 87-103. doi : 10.3406/jsa.1988.1330 http://naturalis.fcnym.unlp.edu.ar/id/20130708012200.

- GENTILE LAFAILLE, M. E., "Sobre la presencia de Huaina Capac en Chile", ponencia al XIer. Congreso Nacional de Arqueología Argentina. San Rafael, Mendoza. (1994). 
- GENTILE LAFAILLE, M. E., "Dimensión sociopolítica y religiosa de la capacocha del cerro Aconcagua", en Boletín del Instituto Francés de Estudios Andinos (Lima), 25 (1) (1996) 43-90.

http://naturalis.fcnym.unlp.edu.ar/id/20130708012204

- GENTILE LAFAILLE, M. E., "La pichca: oráculo y juego de fortuna (su persistencia en el espacio y tiempo andinos)", en Boletín del Instituto Francés de Estudios Andinos (Lima), 27 (1) (1998) 75-131.

http://naturalis.fcnym.unlp.edu.ar/id/20130708012206

- GENTILE LAFAILlE, M. E., "Presencia incaica en el "paisaje de acontecimientos' de un sector de la puna de Jujuy: huanca, usnu, cachauis y quipildor", en Boletín de Arqueología PUCP (Lima), 7 (2003) 217-262. http://revistas.pucp.edu.pe/index.php/boletindearqueologia/article/view/1992/ 1923.

- GENTILE LAFAILLE, M. E., "Tocapu: unidad de sentido en el lenguaje gráfico andino", en Revista Espéculo (Madrid), 45 (2010) 1-25.

http://www.ucm.es/info/especulo/numero45/tocapu.html.

- GENTILE LAFAILLE, M. E., "Mamacuna y monjas de clausura. Notas para unos derroteros institucionales andinos (siglos XV-XVI)", en Simposium (San Lorenzo del Escorial), XIX Edición (2011b) 1076-1092. http://naturalis.fcnym.unlp.edu.ar/id/20131007012228.

- GENTILE LAFAILLE, M. E., “Objetos prehispánicos legados en testamentos de indios (gobernación de Tucumán, 1608 y 1619)", en Revista AEquitas (Valladolid), 2 (2012a) 9-43.

http://naturalis.fenym.unlp.edu.ar/id/20130711012234 http://revistaaequitas.files.wordpress.com/2012/08/margarita-gentile1.pdf.

- GENTILE LAFAILLE, M. E., "Geografía y política. La gobernación de Tucumán en 1582, según la Relación de Pedro Sotelo Narváez", en Anuario Jurídico y Económico Escurialense (San Lorenzo del Escorial), XLV (2012b) 581-608. https://dialnet.unirioja.es/servlet/articulo?codigo=3867631.

- GENTILE LAFAILLE, M. E., "El censo de los runa: datos y reflexiones sobre los incas en el Collasuyu", en Nueva Corónica (Lima), 2 (2013) 91-120. http://naturalis.fcnym.unlp.edu.ar/id/20161201014341.

- GENTILE LAFAILLE, M. E., "La fundación incaica del oráculo capacocha en el Collasuyu: secuelas de una nota a pie de página", en Revista Cruz del Sur (San Isidro, prov. de Buenos Aires), 22 (2017a) 11-83. http://naturalis.fcnym.unlp.edu.ar/id/20171211014918. 
- GENTILE LAFAILLE, M. E., "El Amaru como emblema de los Incas del Cusco (siglos XVI-XVII)", en Revista El Futuro del Pasado (Salamanca), 8 (2017b) 297-327. doi: <http://dx.doi. org/10.14516/fdp http://naturalis.fcnym.unlp.edu.ar/id/20171211014917.

- GENTILE LAFAILLE, M. E., "Iconología de un diseño incaico en Llullaillaco", en Revista Cruz del Sur (San Isidro, prov. de Buenos Aires), 26 (2017c) 127-179.http://www.revistacruzdelsur.com.ar/Numeros_021-030/RHCZDS02603 -Gentile_Lafaille-Iconologia.pdf.

- GENTILE LAFAILLE, M. E., "Vulcanismo y terremotos andinos. Alcance sociopolítico y religioso de algunas creencias en el siglo XVI", en Anuario Jurídico y Económico Escurialense (San Lorenzo del Escorial), LI (2018a) 501-520. http://naturalis.fcnym.unlp.edu.ar/id/20190916016029.

- GENTILE LAFAILLE, M.E., "Placas zumbadoras y sogas sibilantes asociadas a las capacochacuna del volcán Llullaillaco", en Revista El Futuro del Pasado (Salamanca), 9 (2018b) 15-42.

http://dx.doi.org/10.14516/fdp.2018.009.001.001.

http://naturalis.fcnym.unlp.edu.ar/id/20181010015455.

- GENTILE LAFAILLE, M. E., "Dos comentarios a la libreta de viaje a Doncellas de Pablo G. Haedo (1942?)", en Libro de Resumenes XX Congreso Nacional de Arqueología Argentina (Córdoba), (2019a) 733-734.

https://suquia.ffyh.unc.edu.ar/handle/suquia/3491.

- GENTILE LAFAILLE, M. E., "Etnohistoria de una prenda incaica poco común: el uncu monocromo (área andina argentina)", en Revista Cruz del Sur (San Isidro, prov.de Buenos Aires), 33 (2019b) 11-92. http://www.revistacruzdelsur.com.ar/Numeros_031-040/RHCZDS-03301Gentile_Lafaille-Etnohistoria_uncu_monocromo.pdf.

- GENTILE LAFAILLE, M. E., "Arte, religión y política: etnohistoria de algunas prendas litúrgicas incaicas procedentes de Llullaillaco”, en prensa 2020.

- GONZÁLEZ, A. R., "Patrones de asentamiento incaico en una provincia marginal del imperio", en Revista Relaciones de la Sociedad Argentina de Antropología (Buenos Aires), XIV (1) (1980) 63-82.

http://www.saantropologia.com.ar/textos/patrones-de-asentamiento-incaicoen-una-provincia-marginal-del-imperio/.

- GONZÁLEZ, A. R., “Las ‘provincias’ Inca del antiguo Tucumán”, en Revista del Museo Nacional (Lima), XLVI (1982) 317-380. 
- GUAMÁN POMA DE AYALA, P., El primer Nveva Coronica i Bven Gobierno conpvesto por don... c. 1615. http://www.kb.dk/elib//mss/poma

- HAEDO, P. G., Libreta de viaje a Doncellas. Ms., 1941. Copia digital facilitada por M.L. Fuchs.

- MATIENZO, J. de, Gobierno del Perú, Lima [1567] 1967.

- OTTONELLO DE GARCIA REINOSO, M., "Instalación, economía y cambio cultural en el sitio tardío de Agua Caliente de Rachaite", Publicación de la Dirección de Antropología (Jujuy), 1 (1973) 23-68.

- ROLANDI DE PERROT, D., "Un hallazgo de objetos metálicos en el área del Río Doncellas, Jujuy", en Revista Relaciones de la Sociedad Argentina de Antropología (Buenos Aires), VIII (1974) 153-160.

http://www.saantropologia.com.ar/textos/un-hallazgo-de-objetos-metalicos-enel-area-del-rio-doncellas-provincia-de-jujuy/.

- RAFFINO, R. A., Los Inkas del Kollasuyu. Origen, naturaleza y transfiguraciones de la ocupación inka en los Andes meridionales, La Plata (provincia de Buenos Aires) 1982.

- REINHARD, J., "A 6,700 metros niños incas sacrificados quedaron congelados en el tiempo", en Revista National Geographic (Washington), (1999) 36-55. http://www.johanreinhard.net

- SANTA CRUZ PACHACUTI YAMQUI SALCAMAYGUA, J. de, Relación de antiguedades deste reyno del Piru, [1613?]. http://bdh.bne.es/bnesearch/ detalle/bdh0000087346.

- SCHOBINGER, J.; AMPUERO, M., y GUERCIO, E., "Descripción de las estatuillas que conformaban el ajuar acompañante del fardo funerario hallado en el cerro Aconcagua (Provincia de Mendoza)", Relaciones de la Sociedad Argentina de Antropología (Buenos Aires), XVI (1984-1985) 175-189.

http://www.saantropologia.com.ar/textos/estatuillas-del-ajuar-del-fardo-funerariohallado-en-el-cerro-aconcagua/

- SERRANO, A., Manual de la cerámica indígena, Córdoba 1966.

- SUETTA, J. M., y ALFARO DE LANZONE, L. C., "Excavaciones arqueológicas en el Pucará de Rinconada, provincia de Jujuy", en Actas de las Jornadas de Arqueología del Noroeste Argentino, Buenos Aires 1978, pp. 297-382. 
- VALENCIA ZEGARRA, A., "Las microesculturas de Saqsaywaman", en Revista Saqsaywaman (Cusco), 1 (1970) 159-177.

\section{Webgrafia}

- MUSEO DE ARQUEOLOGÍA DE ALTA MONTAÑA, SALTA. www.maam.gob.ar. 